\title{
Financial integration of East Asian economies: evidence from real interest parity
}

\begin{abstract}
In this article, we investigate the financial linkages between the East Asian economies with Japan and the United States. We test for long-run Real Interest-rate Parity (RIP) using an array of panel-data techniques, including recent techniques developed by Breuer et al. (2002) and Carrion-i-Silvestre et al. (2005). This study offers two important results: first, the failure to account for structural breaks in the industrialized countries and Asian emerging economies is likely to provide evidence of nonstationary series that are stationary. Second, we found strong evidence that the parity condition holds in all the Asian countries. The failure of earlier studies to confirm mean reversion of Real Interest-rate Differential (RID) may reflect the choice of estimation/testing procedure rather than any inherent deficiency in the RIP.
\end{abstract}

Keyword: East Asian; Economies; Real interest-rate parity (RIP) 